\title{
Correlations Between Root Length and Face Size
}

\author{
S. M. GARN, B. H. SMITH, and P. E. COLE
}

Center for Human Growth and Development, University of Michigan, Ann Arbor, Michigan 48109

\section{J Dent Res 59(2):141, February 1980}

Mandibular tooth root lengths, as measured on oblique-jaw radiographs, are systematically intercorrelated, with a declining "distance" gradient from adjacent teeth to those more remote in the dental arch (Garn et al., J Dent Res 57:270, 1978). They also exhibit low-order positive correlations with the corresponding crown diameters, despite temporal differences in crown completion and completion of root elongation (Garn et al., J Dent Res 57:636, 1978). The question, therefore, arises as to the relationship between root lengths and facial diameters, and the existence of a general "size" factor linking crowns, roots and the bony face.

Accordingly, we have made use of root lengths of C-M2, measured as previously described, and 3 facial perimeter measurements on 122 Michigan adolescents, 16-17 years of age. Landmarks included Nasion, Articulare and Gnathion, as located on lateral-skull radiographs of each subject. Derived diameters included face length (N-Gn), face depth (N-Ar) and jaw length (Ar-Gn). Correlations were first sex-specific and then pooled, using the $z$ transform of $r$, thereby reducing the total number of $r$ from 30 to 15 .

As shown in the table, correlations between root length and face size were systematically positive, though of a low order of magnitude averaging close to 0.15 overall. The highest correlations generally involved jaw lengths (Ar-Gn), most of which were individually significant at $p \leq 0.05$. The overall trends were highly significant by the sign test $(15: 0)$, ignoring questions of independence. In a separate approach, individuals in the upper and lower deciles for root length were compared for facial dimensions. Those with the longest roots generally exceeded those with short roots in all three facial dimensions by a maximum

Received for publication December 18, 1978 . Accepted for publication June 19, 1979.

This study was supported, in part, by Grant DE-03610 from the National Institutes of Health. of $7 \mathrm{~mm}$ (e.g., $\mathrm{M} 2$ root length and jaw length). Conversely, individuals in the top ten percent for any facial dimension exceeded those in the bottom ten percent for that face dimension in root length by as much as $1.3 \mathrm{~mm}$ (again for $\mathrm{M} 2$ length and jaw length). On a percentage basis, those with the longest M2 root length showed a six percent increase in jaw length over the short M2 root length group. Those in the upper decile for jaw length showed a nine percent increase in root length, as compared with the lowest jaw length decile group.

As pointed out previously for root length intercorrelations (Garn et al., J Dent Res 57:270, 1978), neither small differences in subject positioning, nor systematic effects of jaw geometry would result in the clearcut and systematic relationships between root length and face size observed here. Rather, the evidence supports the notion of a low order, general size factor involving crowns, roots and faces, not unlike that linking crown size to body size and head size alike (Filipsson and Goldson, Acta Odont Scand 21:359, 1963; Garn et al., J Dent Res 47:1197, 1968).

\section{TABLE}

ROOT LENGTH/FACE SIZE CORRELATIONS FOR 5 MANDIBULAR TEETH

\begin{tabular}{lcccc}
\hline & & \multicolumn{3}{c}{ Correlation with } \\
\cline { 3 - 5 } $\begin{array}{l}\text { Mandibular } \\
\text { tooth }\end{array}$ & $\mathrm{N}$ & $\begin{array}{c}\text { Face } \\
\text { length }\end{array}$ & $\begin{array}{c}\text { Face } \\
\text { depth }\end{array}$ & $\begin{array}{c}\text { Jaw } \\
\text { length }\end{array}$ \\
\hline $\mathrm{C}$ & 105 & .02 & .06 & .15 \\
P1 & 109 & .15 & .12 & $.23^{*}$ \\
P2 & 112 & .06 & .07 & $.25^{*}$ \\
M1 & 113 & .03 & .08 & $.28^{*}$ \\
M2 & 101 & .14 & .15 & $.30^{*}$ \\
Mean r & & .08 & .10 & $.24^{*}$ \\
\hline
\end{tabular}

*Significant at $\mathrm{p} \leq 0.05$ 